\title{
Long-term visibility variation at the Ebro Observatory (1960-2020).
}

\author{
Juan José Curto (1), Nicolás Tacoronte $(1,2)$ \\ (1) Observatorio del Ebro, (OE) CSIC - Universitat Ramón Llull \\ (2) Universidad Complutense de Madrid \\ Corresponding author: J.J. Curto (jjcurto@obsebre.es)
}

Abstract.

This study explores the interdecadal variability and trends of surface horizontal visibility in the Baix Ebre area (Spain) from 1960 to 2020, using the historical archive of the Ebro Observatory located in the town of Roquetes, in the centre of the region. We detected a prominent improvement in visibility in the first decades of the second part of the twentieth century but this was followed by a dramatic deterioration in the last decade recorded (2010-2020). This was not accompanied by a significant trend in relative humidity over the same period. It was found that very good visibility $(20-50 \mathrm{~km})$ occurred at a frequency of more than $40 \%$ in the $1980 \mathrm{~s}$ and $90 \mathrm{~s}$, while this percentage dropped to just $15 \%$ during the $2010-2020$ decade.

Visibility was found to be negatively correlated with relative humidity and positively correlated with wind speed. This correlation was statistically valid for most of the time periods we looked at. Wind regime, prevailing wind direction and the corresponding origin (marine or continental) of the air mass were found to display a strong influence on the short-term visibility levels at the Ebro Observatory. However, long term visibility trends are controlled by other factors, which are probably of anthropogenic origin. The rapid increase in population in Roquetes and other neighbouring towns during recent decades could be the cause of the implicit impairment of air quality observed because of increased levels of air pollution on a regional scale. Apart from these local sources, visibility at the Ebro Observatory could also be influenced by the aerosol load from neighbouring regions (Castelló and Tarragona) which have a significant concentration of industries.

Keywords: visibility, humidity, wind, interdecadal variability.

\section{Introduction.}

Atmospheric visibility is defined as the maximum distance a black object of suitable dimensions (located close to the ground) can be seen and recognized when viewed against a sky background during the day or the distance it could be seen and recognized at night at if the general lighting was raised to the normal daytime level (World Meteorological Organization [WMO], 1992). It represents one of the dominant features of the climate and landscape of an area (Founda et al., 2016). Three fundamental factors make visibility measurements difficult to carry out: local meteorology, the physiology of the human eye and, finally, the characteristics of the object to be viewed with respect to the surrounding background.

Many studies have been performed on rural and urban areas in different countries, e.g. Taiwan (Tsai, 2005), United Kingdom (Doyle and Dorling, 2002), China (Deng et al., 2012), India (Hu, 2017), United States (Sloane, 1982), Iran (Sabetghadam, 2012), Hungary (2008) and Greece (Founda et al., 2016). The main objective of our study is to understand the changes that have occurred in atmospheric visibility from 1960 to the present day at the Ebro Observatory, a Spanish observatory with a long history of records. To do this, we analysed the annual and seasonal variability of the visibility. Data were grouped using different scales, such as those recommended by the World Meteorological Organization (WMO), but in some parts of this study, other adhoc adapted classifications were used with the recorded values. We checked how the trends in the observations vary for different periods of time. The records of relative 
humidity and the wind regime were also studied, examining the relationships between these variables and visibility.

\subsection{Area of study.}

56

The Ebro Observatory $\left(40.8^{\circ} \mathrm{N}, 0.5^{\circ} \mathrm{E}\right)$ is located in the Eastern quadrant of the Iberian Peninsula (Figure 1). It is a centre devoted to geophysical observations. It works in coordination with the National Meteorological Agency (AEMET), and, in addition, it collaborates with other official and private organizations in the same line of research. It was founded in 1904 with the aim of studying the relationships between the Earth and the Sun (Cirera, 1906; Puig, 1927; Cardús, 1983). Since then, a wide variety of records of great scientific value have been accumulated, such as magnetic, ionospheric and seismic archives, which are considered to make up one of the most extensive collections of data in Spain. In fact, our meteorological archives date back to the year 1880. As a result of this, we have a long series of meteorological data that allows us to carry out climate studies of the Ebro and, by extension, the Mediterranean region (Curto et al., 2008). Among all these data, there is a historical series of atmospheric visibility. The last sixty years of these records have been digitized and we have worked with them analysing trends and relationships with meteorological variables and also with other effects linked to human activity (Curto et al., 2008).

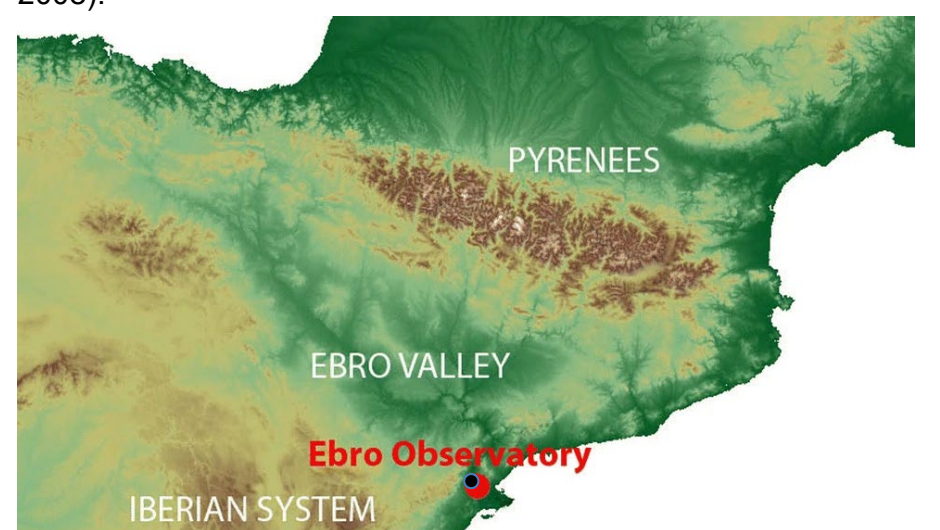

\footnotetext{
Figure 1: Topographic map showing the location of the Ebro Observatory (black dot) at the end of the Ebro Valley, close to the Ebro river delta and the Mediterranean Sea. The red circle describes the mean distance achieved with visibility observations.
} 
The data from the Observatory's meteorological stations are particularly suitable for ascertaining the existence of possible climatic changes or fluctuations, as it is an observation point that has never moved nor experienced significant changes in its surroundings from 1910 onward (Raso, 1987).

\subsection{Climatic characteristics of the site.}

The Ebro basin includes a gradient from Atlantic to Mediterranean climates, and has complex topography, geology and land cover (López-Moreno et al., 2013). This heterogeneous topography and the influence of various large-scale atmospheric patterns, like the North Atlantic Oscillation, the Mediterranean Oscillation and the Western Mediterranean Oscillation (Vicente-Serrano et al., 2009; Vicente-Serrano and Lopez-Moreno, 2006) generate a complex spatial distribution of climate parameters (López-Moreno et al., 2011).

Specifically, for this area, the climate is mild in general. The air temperature rarely drops to zero degrees and hardly ever rises above $34^{\circ} \mathrm{C}$, resulting in a moderate and temperate series of values. The depressions of the Mediterranean produce strong winds, although not cold, which are channelled by the Ebro valley (Figure 1). The NNW wind predominates in the winter months and the SSE breeze predominates in summer (Cirera, 1910).

\section{Data and methodology.}

The visibility data have been continuously measured at the same site with a surface weather station. We worked with the data corresponding to atmospheric visibility, wind speed and direction and relative humidity. We focused on the 07:00 LT, 13:00 LT, and 18:00 LT observations as being representative for morning, noon, and afternoon or evening conditions.

The available visibility data were taken by specialized observers and entered in notebooks by hand. Rotating shifts involved different observers so any hypothetical personal bias was compensated for. Regarding our data analysis, first of all, it was necessary to locate the existence of gaps and outliers that may contribute to errors in the results. With this in mind, a code was created that separates the days for which no data were found and also detects those cases that are considered to present a problem with the aim of trying to solve it. The criterion used consists in eliminating those values greater than 1.5 times the interquartile range below the first quartile and above the third for each hour of the day. However, the relative humidity and wind speed and direction data were assumed to be valid a priori as they were measured with instrumentation and were verified by a data manager.

To study the visibility variations, temporal averages were taken, using group divisions of years, months or weeks. To study how the collected horizontal visibility data vary throughout the study period, they were divided based on an empirical scale of visibility classes, as recommended by the World Meteorological Organization, WMO (Wang et al. 2010). This scale is displayed in Table 1. 
Table 1: Visibility classes of WMO directive.

\begin{tabular}{|c|c|c|c|c|c|c|c|c|c|}
\hline Class & 1 & 2 & 3 & 4 & 5 & 6 & 7 & 8 & 9 \\
\hline Visibility $(\mathrm{km})$ & $0.050-0.2$ & $0.2-0.5$ & $0.5-1$ & $1-2$ & $2-4$ & $4-10$ & $10-20$ & $20-50$ & $>50$ \\
\hline
\end{tabular}

On the other hand, a similar study was carried out with the wind direction and intensity data, and so diagrams were obtained representing the frequency with which winds from a certain direction occurred depending on the time of year. It is also possible to relate these data to the recorded atmospheric visibility measurements. In this way, the representations of the visibility variations were obtained as a function of the sectors from which the wind comes, or by relating the wind speed to the direction from which the wind comes from.

Finally, the correlation coefficient between visibility and relative humidity or wind was calculated.

\section{Results.}

\subsection{Variations in the visibility.}

138

It can be verified that visibility presented gradual variations throughout most of the years in the last century (Founda et al., 2016), but, at the Ebro Observatory, a significant and more abrupt increase appeared in the decade 1980-1990, followed by a subsequent decrease that became even more abrupt in the last decade recorded (2010-2020) (Figure 2). On a global scale, Wang \& Liang (2009) showed a decrease in visibility between 1973 and 2007, which was interpreted as being down to a higher concentration of aerosols and their impact on incident solar irradiance. A significant decrease in visibility was observed in Asia, South America, Australia and Africa, while in Europe visibility increased after the 1980s as a result of air pollution mitigation measures (Vautard et al., 2009).
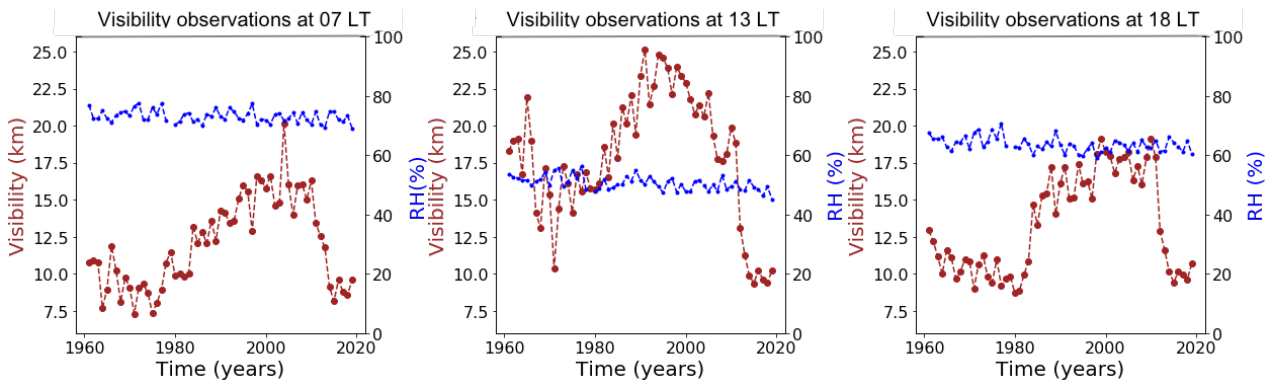

Figure 2: Annual average of visibility (red dots) and relative humidity (blue dots) measurements between 1961 and 2019.

We also found it useful to study the monthly variation in visibility (Figure 3). The differences that appeared between seasons may be due to certain factors such as the variation in relative 
humidity throughout the year, since this may be indicative of precipitation or fog, which would reduce visibility, or the recorded type of wind blowing in this area, which can clean the atmosphere of suspended particles and pollutants leading to better visibility results, or to worse results, depending on the area from which the wind blows.
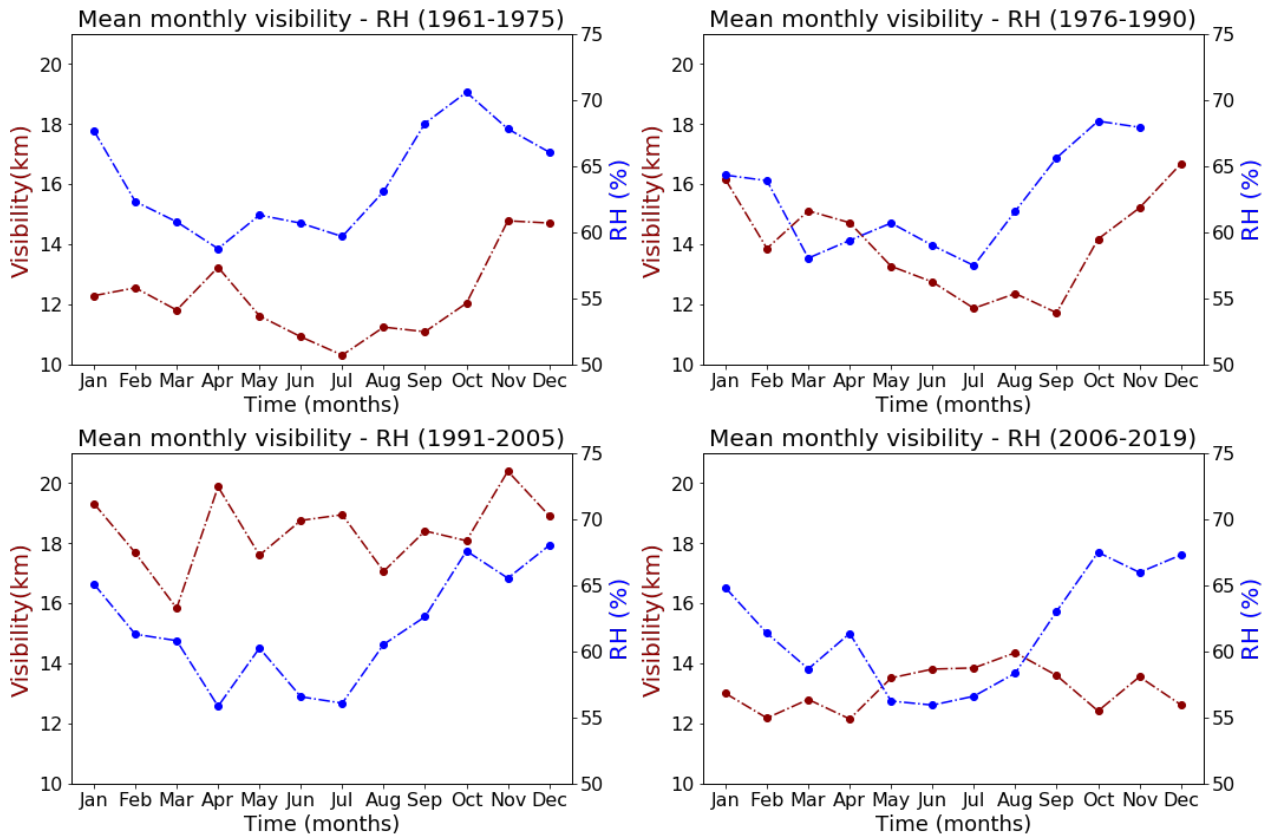

Figure 3: Average of monthly visibility (red line) and relative humidity (blue line) measurements between 1961 and 2019 in 15-year periods.

The results shown in Figure 3 indicate that, in general, the maximum average visibility was found during the winter months and the minimum in July, August and September, except for the last period of time measured. The correlation of these results with those of relative humidity will be presented later, but from this representation it can already be seen that there is no clear dependence between the two variables. With the average relative humidity values that have been represented, the hypothesis that fog or precipitation are factors to be highlighted in the global change in visibility can be ruled out.

Finally, to study how the horizontal visibility data vary throughout the studied period, we grouped them according to the aforementioned empirical scale of visibility classes recommended by the WMO (Wang et al. 2010). 

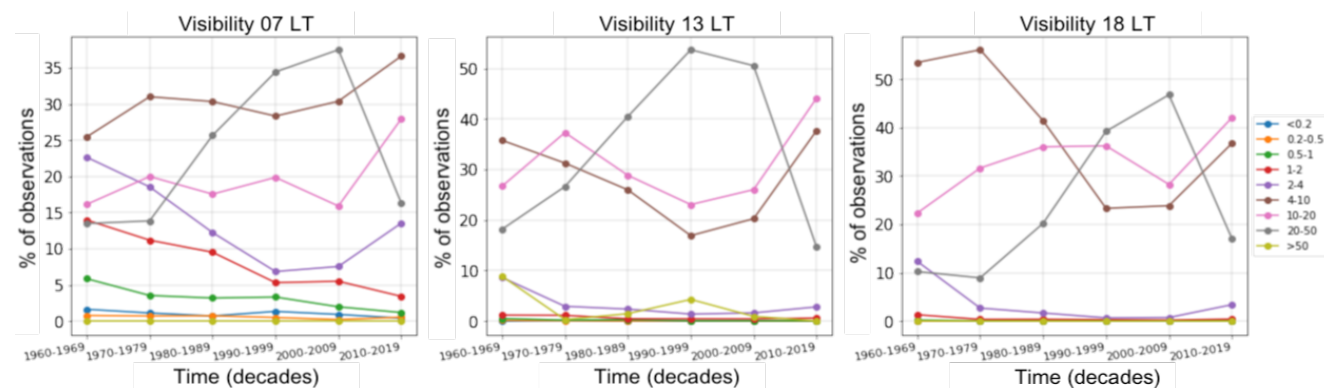

Figure 4: Temporal evolution of visibility for each decade according to the class scale defined by the WMO for

178

179

180

181

182

183

184

185

186

187

188

189

190

191

192

193

194

195

196

197

198

199

200

201

202

203 07:00 LT, 13:00 LT and 18:00 LT.

A remarkable increase in the visibility observations of the largest class with time can be appreciated in Figure 4. During the 1960s, the majority of observations fell into class 6 , while in the period 2000-2010, the most frequent were class 8 ones. In the last decade, however, this trend changed, registering a greater number of class 7 observations. The minor class observations, on the other hand, make up a minority in the global computation and do not significantly affect the mean. As in the representation of Figure 2, here it can be observed that visibility had been increasing until 2010, when there was a clear decrease, of up to $10 \mathrm{~km}$, noted in the average visibility.

\subsection{Wind data study.}

For the study of the wind, we took into account intensity and direction data. To characterize the wind, the wind speed recorded at 07:00 LT, 13:00 LT and 18:00 LT in each sector was studied, differentiating it into 3 large groups: less than $5 \mathrm{~m} / \mathrm{s}$, between $5 \mathrm{~m} / \mathrm{s}$ and $10 \mathrm{~m} / \mathrm{s}$ and greater than $10 \mathrm{~m} / \mathrm{s}$ (Figure 5). It was also necessary to know the relationship between the sectors from which the wind came and the visibility as well as the time of the year in which the measurements were recorded in the different sectors.

Due to the local orography, there are two favoured directions for the wind. Winds are conditioned by the shape of this section of the Ebro basin: from the upper part of the region, the area is open to the Ebro basin and terrestrial winds (mistral, NW) have easy access, whereas for the lower part, the area is open to the delta of the Ebro river which is connected to the Mediterranean flow inlets (sea breeze, E and SE). This is linked to infrequent and not very persistent storms. The whole area is located facing away and far from the Atlantic storms associated with the ábregos winds (W and NW) (Pedraza and García, 2013).
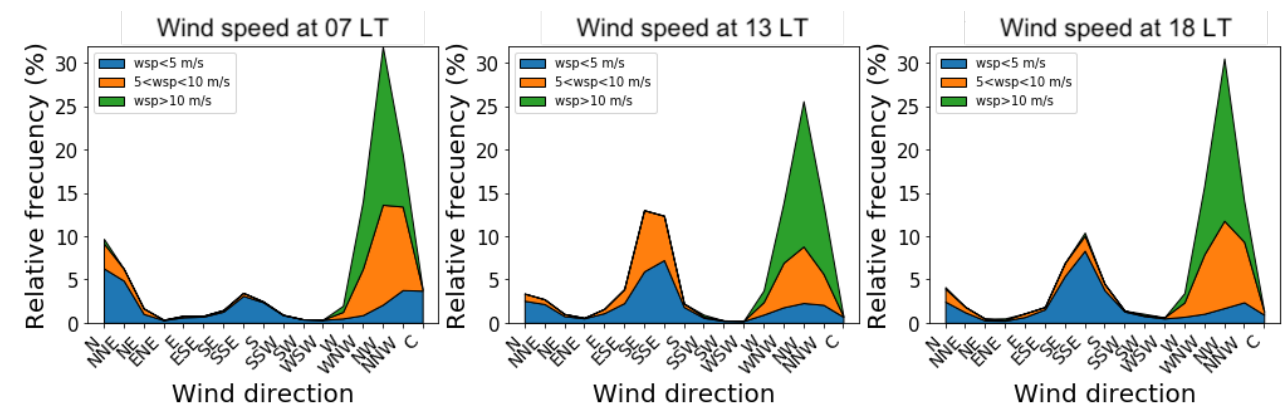
Figure 5: Relative frequencies of the number of measurements with respect to the surface wind directions for three categories of wind speed (wsp). Soft (blue), medium (orange), and strong (green) at 07:00 LT (left), 13:00 LT (centre), and 18:00 LT (right). Sector C refers to periods of calm (wsp $<0.5 \mathrm{~m} / \mathrm{s})$.

208

209

210 wind.

The SSE-SSW sectors are linked to the transport of air masses from arid areas of North Africa, frequently associated with dust events that affect wide areas of the Mediterranean. Temperate and humid winds with a Mediterranean origin from here are less intense than the north wind (Figure 5). There is an increase in the wind records for these southern winds at 13:00 LT due to the influence of the sea breeze (Serrano et al. 2017). In Figure 7 it can be seen that the wind coming from these regions is associated with minimum visibility and, as indicated in Figure 6, it is more common to find it in summer. On the other hand, in the colder months, stronger winds coming from the W-NW directions (Figure 6) are the prevailing ones. These winds, called gale winds, are the ones that reach the highest speeds (Figure 5). They are cold, dry, turbulent and are associated with maximum visibility (Figure 7).

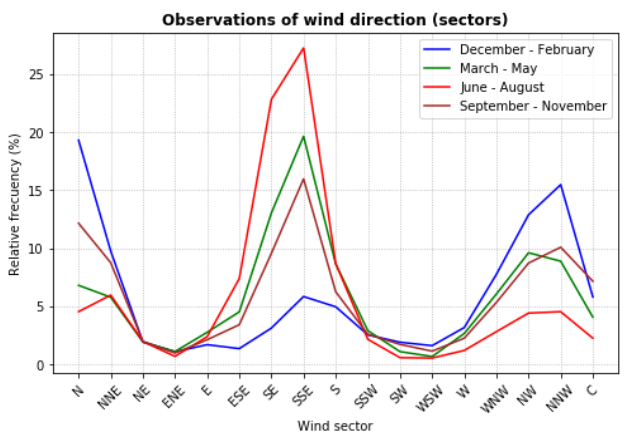

Figure 6: Visibility variation for each wind direction (sector) and for each season of the year.

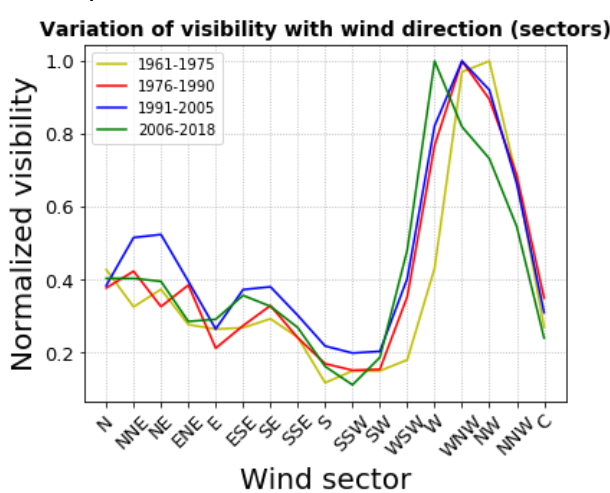

Figure 7: Relative frequencies of the number of measurements recorded in each wind direction (sectors) during different sub periods into which we have divided the series. 
The clearest feature we found is that an increase in relative humidity causes a decrease in visibility, as shown by the dominant negative correlations represented in Figure 8. According to Lawal (2014), the relation:

$$
t_{n-2}=\frac{r \sqrt{n-2}}{\sqrt{1-r^{2}}} \rightarrow r>\frac{t_{n-2}}{\sqrt{n-2+t_{n-2}^{2}}}
$$

indicates when the correlation coefficient of the sample, $r$, is significant. $n$ is the number of points and $t_{n-2}$ refers to the Student's $t$ coefficient for $n-2$.

In our study, for the selected data, the correlation coefficient begins to be significant when it is greater than 0.1453 (95\% of confidence, from relation (1), with $n>30$ ), which occurs in all the years studied, as shown by the time series in Figure 8.

There is an increase in correlation in the central part of the period studied, possibly due to the harsh economic times and the subsequent effects on pollution following the 1970s energy crisis. During this period of great visibility, natural sources such as humidity and wind were more significant in accounting for the variability in visibility.

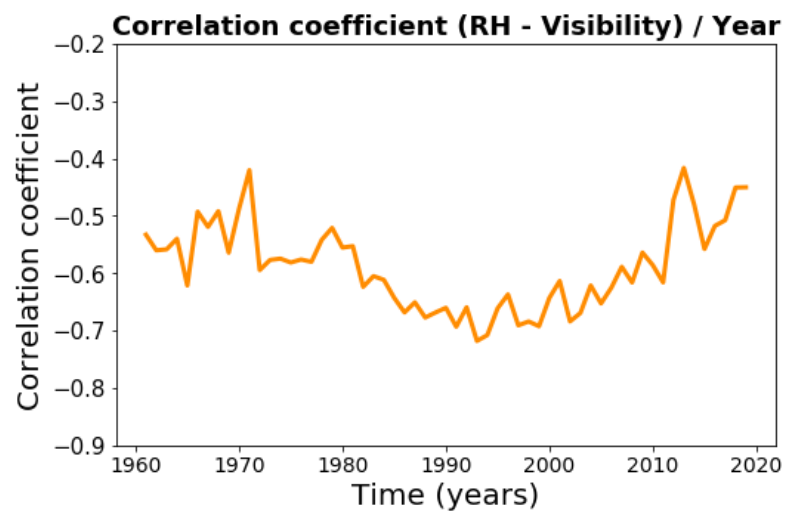

Figure 8: Correlation coefficient between annual relative humidity, $\mathrm{RH}$, and visibility. The adjustment has been made by taking the 3 daily visibility data and $\mathrm{RH}$ measurements.

As regards the contribution of the wind, the different correlations with visibility have been calculated in the same way as for relative humidity. On this occasion, in addition, the longterm trends (trending series) were removed from the visibility series because they were clearly not related to the wind. In this way, it can be observed that the correlations for the entire period, shown in Table 2, increased and stabilized, and were negative for wind from the ESE-SSW sectors and positive from the NW directions, due to the different types of wind already mentioned.

Table 2: Correlation coefficients between wind and visibility at 07:00 LT, 13:00 LT and 18:00 LT for the measurements taken during the period 1961- 2019 in which the wind came from the NW or ESE-SSW directions, once long-term trends were removed. Non-significant correlations are indicated by the sign "-".

\begin{tabular}{|l|l|}
\hline January-March & April-June \\
\hline
\end{tabular}




\begin{tabular}{|c|c|c|c|c|c|c|}
\cline { 2 - 7 } \multicolumn{1}{c|}{} & $07 \mathrm{LT}$ & $13 \mathrm{LT}$ & $18 \mathrm{LT}$ & $07 \mathrm{LT}$ & $13 \mathrm{LT}$ & $18 \mathrm{LT}$ \\
\hline \multirow{2}{*}{$\mathrm{N}-W$} & 0.5 & 0.3 & 0.17 & 0.64 & 0.29 & 0.53 \\
\hline ESE-SSW & - & -0.24 & - & -0.18 & -0.23 & - \\
\hline & \multicolumn{5}{c}{ July-September } & \multicolumn{3}{c|}{ October-December } \\
\cline { 2 - 7 } & $07 \mathrm{LT}$ & $13 \mathrm{LT}$ & $18 \mathrm{LT}$ & $07 \mathrm{LT}$ & $13 \mathrm{LT}$ & $18 \mathrm{LT}$ \\
\hline \multirow{2}{*}{ N-W } & 0.72 & 0.43 & 0.55 & 0.60 & 0.36 & 0.44 \\
\hline ESE-SSW & -0.24 & -0.20 & - & -0.30 & -0.24 & - \\
\hline
\end{tabular}

\section{Conclusions}

Long-term variations in visibility over periods of years are the most important ones and may be explained in terms of the concentration of aerosols, which saw a significant decrease in Europe due to pollution mitigation measures at the end of the 20th century. In the last decade, however, there has been a prevailing steep decline in visibility.

The study carried out by us using the local wind regime indicates a clear distinction between the winds coming from the SSE-SSW sectors and those coming from the W-NW which, due to the local orography, are the most predominant in the area. The SSE-SSW winds are less intense yet more frequent in summer. They are associated with minimum visibility values, as indicated by the negative correlation coefficient obtained when comparing the data of both variables. However, the W-NW winds are the most intense ones recorded at the Observatory site. They are more frequent in winter and are associated with maximum visibility.

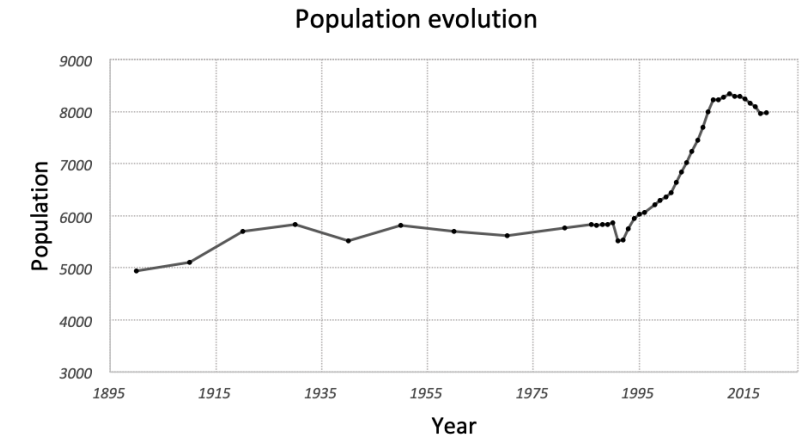

Figure 9: Variation of the population in the municipality of Roquetes, home to the Ebro Observatory, between 1900 and 2020.

Finally, and with the results obtained in the previous section, it can be concluded that, in the short term, relative humidity and wind have a significant influence on visibility. However, in the long term, other factors, which may include pollution, are more decisive. It is noteworthy that 
from the year 2000 onward there has been a large increase in the population of the town of Roquetes where the Ebro Observatory is located and where the measurements were taken (Figure 9). Similar increases in population have been seen in neighbouring towns such as Tortosa or Amposta, both within the scope of the visibility area we are studying. An increase in industrial activity and/or the traffic this entails may be the reason that an increase in pollutants was recorded and a corresponding reduction in visibility. As a conclusion, we can affirm that the long-term variability of visibility at the Ebro Observatory as representative of the Baix Ebre region cannot be explained by natural factors and, thus, other factors such as an increase in man-made pollution should be taken into consideration.

\section{Acknowledgments}

The authors wish to acknowledge the great contribution of the meteorological observers of the Ebro Observatory with their huge commitment over the years in assessing, recording and digitizing the visibility, relative humidity and wind data used in this work. We further extend our gratitude to AEMET for supporting the observers' work by allowing us to have these climatological series.

\section{References}

Cardús, J.O. (1983). El Observatorio del Ebro, Memoria Num. 14, Sugrañes, Roquetes.

Cirera, R. (1906) «Noticia del Observatorio del Ebro y de algunas observaciones del eclipse de 30 de Agosto de 1095», Memorias del Observatorio del Ebro n 1, Barcelona, G. Gili Ed.

Cirera, R. (1910). Prólogo: El Observatorio del Ebro. Boletín mensual del Observatorio del Ebro, vol. 1, p. 7-14.

Curto, J. J., Also, E., Pallé, E. and Solé, J. G. (2008). Sunshine and synoptic cloud observations at Ebro Observatory, 1910-2006. Int. J. Climatol, vol. 28.

Deng, J., Du, K., Wang, K., Yuan, CS and Zhao J. (2012). Long-term atmospheric visibility trend in Southeast China, 1973-2010, Atmospheric Environment, 59, 11-21, 10.1016/j.atmosenv.2012.05.023.

Doyle, M. and Dorling, S. (2002). Visibility trends in the UK 1950-1997, Atmospheric Environment, 36(19), 3161-3172. https://doi.org/10.1016/S1352-2310(02)00248.

Founda, D., Kazadzis, S., Mihalopoulos, N., Gerasopoulos, E., Lianou, M., and Raptis, P. I. (2016). Long-term visibility variation in Athens (1931-2013): a proxy for local and regional atmospheric aerosol loads. Atmospheric Chemistry and Physics, 16(17), 11219-11236.

García de Pedraza, L. and García Vega, J. (2013). Notas climáticas para un estudio comparativo entre las cuencas de los ríos Po y Ebro. Agencia Estatal de Meteorología. p. 252255. 
Hu, Y., Yao, L., Cheng, Z. and Wang Y. (2017), Long-term atmospheric visibility trends in megacities of China, India and the United States, Environmental Res., 159:466-473. doi: 10.1016/j.envres.2017.08.018.

Lawal, B. (2014). Applied Statistical Methods in Agriculture, Health and Life Sciences, 115168, Springer. https://doi.org/10.1007/978-3-319-05555-8

López-Moreno, J. I., Vicente-Serrano, S. M., Moran-Tejeda, E., Zabalza, J., Lorenzo-Lacruz, J., and García-Ruiz, J. M. (2011). Impact of climate evolution and land use changes on water yield in the Ebro basin, Hydrol. Earth Syst. Sci.,15, 311-322, https://doi.org/10.5194/hess-15311-2011.

López-Moreno, J.I., Vicente-Serrano, S.M., Zabalza, J., Beguería, S., Lorenzo-Lacruz, J., Azorín-Molina, C. and Morán-Tejeda, E. (2013). Hydrological response to climate variability at different time scales: A study in the Ebro basin, Journal of Hydrology, Volume 477, 175-188, https://doi.org/10.1016/j.jhydrol.2012.11.028.

Molnár, A., Mészáros, E., Imre, K. and Rüll, A. (2002). Trends in visibility over Hungary between 1996 and 2002, Atmospheric environment, 42(11):2621-2629, doi: 10.1016/j.atmosenv.2007.05.012.

Puig, I. (1927). El Observatorio del Ebro: Idea General Sobre el Mismo, Algueró y Baiges, Tortosa,

Raso, J. M. (1987). Variaciones recientes de la temperatura media en el observatorio del Ebro. Madrid, Anales Universidad Complutense, Volume 7,155-165.

Sabetghadam, S., Ahmadi-Givi, F. and Golestani Y. (2012). Visibility trends in Tehran during 1958-2008, Atmospheric Environment, 62:512-520, doi: 10.1016/j.atmosenv.2012.09.008.

Sloane, C.S., (1982). Visibility trends-II. Mideastern United States 1948-1978, Atmospheric Environment, 1967 Vol. 16; Iss. 10, doi:10.1016/0004-6981(82)90117-2

Tsai, Y. (2005). Atmospheric visibility trends in an urban area in Taiwan 1961-2003, Atmospheric environment, 39(30):5555-5567, doi: 10.1016/j.atmosenv.2005.06.012.

Vautard, R., Yiou, P., and Oldenborgh, G. (2009) Decline of fog, mist and haze in Europe over the past 30 years, Nat. Geosci., 2, 115-119, doi:10.1038/ngeo414.

Vicente-Serrano, S. M. and Lopez-Moreno, J. I. (2006). Influence of atmospheric circulation at different spatial scales on winter drought variability through a semi-arid climatic gradient in Nort-east Spain, Int J. Climatol., 26(11), 1427-145

Vicente-Serrano, S. M., Beguería, S. and Lopez-Moreno, J. I., El Kenawy, A. M., and Angulo M. (2009). Daily atmospheric circulation events and extreme precipitation risk in Northeast Spain: the role of the North Atlantic Oscillation, Western Mediterranean Oscillation and Mediterranean Oscillation, J. Geophys. Res., 114, D08106, doi:10.1029/2008JD011492. 
378 Vicente-Serrano, S. M., Camino, E. R., Castro, F. D. and Molina, C. A. (2017). An updated 379 review on recent trends in observational surface atmospheric variables and their extremes over Spain. Cuadernos de Investigación Geográfica/Geographical Research Letters, 43, p. 209-232,

Wang, K., Dickinson, R. E. and Liang, S. (2009). Clear sky visibility has decreased overland globally from 1973 to 2007 , Science, 323(5920):1468-1470.

Wang, Y., Schmid. F. and Harou, A. (2010). Guide to the Global Observing System. Published by: WMO.

390

World Meteorological Organization (1992). "Instrument and observing methods report". Volume 46, 474, Geneva. 